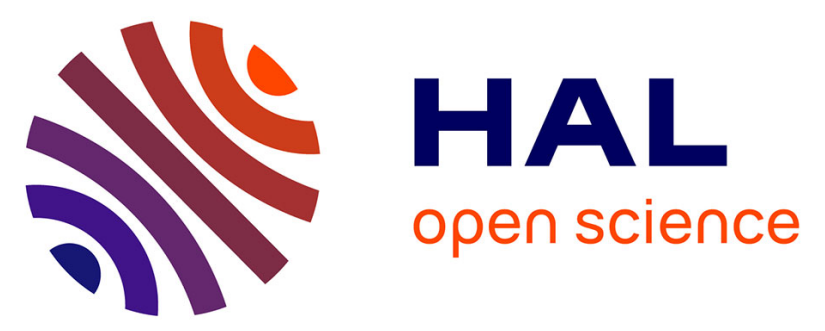

\title{
Biochanin A, the Most Potent of 16 Isoflavones, Induces Relaxation of the Coronary Artery Through the Calcium Channel and cGMP-dependent Pathway
} Thomas Migkos, Jana Pourová, Marie Vopršalová, Cyril Auger, Valérie Schini-Kerth, Přemysl Mladěnka

\section{To cite this version:}

Thomas Migkos, Jana Pourová, Marie Vopršalová, Cyril Auger, Valérie Schini-Kerth, et al.. Biochanin A, the Most Potent of 16 Isoflavones, Induces Relaxation of the Coronary Artery Through the Calcium Channel and cGMP-dependent Pathway. Planta Medica, 2020, 86 (10), pp.708 - 716. 10.1055/a-11589422 . hal-03033813

\section{HAL Id: hal-03033813 \\ https://cnrs.hal.science/hal-03033813}

Submitted on 1 Dec 2020

HAL is a multi-disciplinary open access archive for the deposit and dissemination of scientific research documents, whether they are published or not. The documents may come from teaching and research institutions in France or abroad, or from public or private research centers.
L'archive ouverte pluridisciplinaire HAL, est destinée au dépôt et à la diffusion de documents scientifiques de niveau recherche, publiés ou non, émanant des établissements d'enseignement et de recherche français ou étrangers, des laboratoires publics ou privés. 


\section{Biochanin A, the Most Potent of 16 Isoflavones, Induces Relaxation of the Coronary Artery Through the Calcium Channel and cGMP-dependent Pathway}

\author{
Authors \\ Affiliations \\ 1 Department of Pharmacology and Toxicology, Faculty of \\ Pharmacy in Hradec Kralove, Charles University, Hradec \\ Kralove, Czech Republic \\ 2 INSERM (French National Institute of Health and Medical \\ Research), UMR 1260, Regenerative Nanomedicine (RNM), \\ FMTS, Université de Strasbourg, Faculté de Pharmacie, \\ Illkirch, France
}

Thomas Migkos ${ }^{1}$, Jana Pourová ${ }^{1}$, Marie Vopršalová ${ }^{1}$, Cyril Auger ${ }^{2}$, Valérie Schini-Kerth ${ }^{2}$, Přemysl Mladěnka ${ }^{1}$

Key words

blood vessels, cardiovascular, ex vivo, glycitein, isoflavonoid

received February 3, 2020

revised April 2, 2020

accepted April 13, 2020

Bibliography

DOI https://doi.org/10.1055/a-1158-9422

published online I Planta Med @ Georg Thieme Verlag KG

Stuttgart · New York | ISSN 0032-0943

Correspondence

Assoc. Prof. Přemysl Mladěnka, Pharm. D., Ph. D.

Department of Pharmacology and Toxicology, Faculty of

Pharmacy in Hradec Králové, Charles University

Akademika Heyrovského 1203, 50005 Hradec Králové,

Czech Republic

Phone: + 4204950672 95, Fax: + 420495067170

mladenkap@faf.cuni.cz
E Supporting information available online at http://www.thieme-connect.de/products

\section{ABSTRACT}

The dietary intake of flavonoids seems to be inversely related to cardiovascular mortality. The consumption of isoflavonoids is increasing in the general population, especially due to the use of food supplements and a variety of isoflavonoid-rich foods. However, detailed studies on the vascular influence of individual pure isoflavonoids are mostly missing. For this study, 16 isoflavonoids were initially screened for their vasorelaxant properties on rat aortas. The 2 most potent of them, biochanin A and glycitein, were further tested for the mechanism of action on porcine coronary arteries. They both induced an endothelium independent vascular relaxation, with EC $_{50}$ below 6 and $17 \mu \mathrm{M}$, respectively. Biochanin A, but not glycitein, was able to block the vasoconstriction caused by $\mathrm{KCl}, \mathrm{CaCl}_{2}$, serotonin, and $\mathrm{U} 46619$ in a dose-dependent manner. Another series of experiments suggested that the major mechanism of action of biochanin A was the inhibition of L-type calcium channels. Moreover, biochanin A in relatively small concentrations $(2-4 \mu \mathrm{M})$ interfered with the cGMP, but not cAMP, pathway in isolated coronary arteries. These results indicate that some isoflavonoids, in particular biochanin A, are able to have vasodilatory effects in micromolar concentrations, which is of potential clinical interest for the management of cardiovascular pathologies.

\section{Introduction}

Cardiovascular diseases remain the leading cause of mortality and morbidity worldwide. Among them, ischemic coronary disease and stroke are major culprits of mortality. Hence, vascular function can be considered one of the main targets when developing innovative drugs focused on both the treatment and prevention of cardiovascular disorders.

Indeed, isoflavonoids appear to be related to a lower incidence of myocardial and cerebral infarctions [1], reduced arterial stiffness [2], and blood pressure normalization [3]. Due to their structural similarity to endogenous estrogens, they have affinity to estrogen receptors [4] and are known as phytoestrogens. Their main natural sources are legumes and herbs, such as soybean (Glycine max), red clover (Trifolium pratense), milkvetch (Astragalus sp.), Prunus, Pueraria, and Ononis sp. [5-8]. Isoflavonoid intake in humans is also increasing due to the use of a variety of dairy products, processed food, and food supplements derived from the aforementioned plants $[9,10]$. Most of these species are traditionally used in Chinese medicine, among other things, for the treatment of cardiovascular diseases [7]. The lower incidence of cardiovascular disorders in East Asian populations, compared to those from Western countries, has been also attributed to the higher consumption of isoflavonoids, particularly soy isoflavones [11]. Despite these encouraging epidemiological observations, most of the conducted human studies have investigated the effect of isoflavone-rich diets, 
- Table 1 The chemical structures of the 16 tested isoflavonoids.

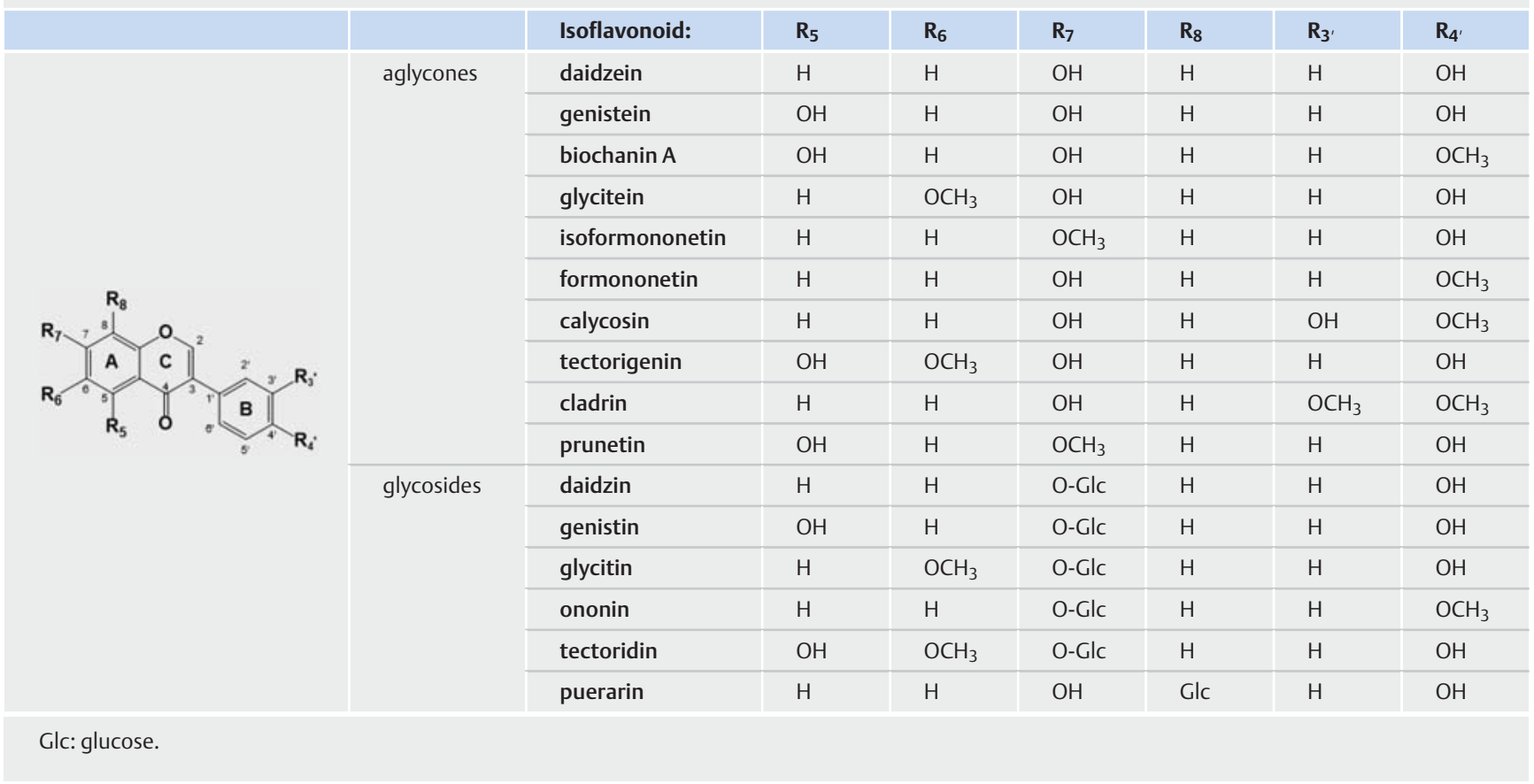

plant extracts, and mixtures of isoflavonoids [1-3]. The data on the effects of individual purified isoflavonoids themselves are hence largely missing, with some exceptions [12]. Additionally, ex vivo and animal vascular studies have been performed for a limited number of compounds $[6,11,13,14]$, and even less information is available in respect to coronary vessels [15-17].

With the present study, we strove to directly compare the vascular effects of 16 pure isoflavones, several of which were tested for the first time, and to further elucidate the mechanism of action of the most active ones, biochanin A and glycitein. Within this framework, we also challenged the hypothesis that biochanin $A$ functions as a calcium channel blocker.

\section{Results}

In the first series of experiments, a screening of the vasodilatory effects of 16 isoflavonoids ( $\triangleright$ Table 1 ) on norepinephrine precontracted rat aortic rings was performed. All glycosides, namely genistin, daidzin, glycitin, ononin, tectoridin, and puerarin, had clearly very low vasorelaxant effects, which were comparable to that of the control containing only the solvent (Fig. 1S, Supporting Information) and hence much lower than that of their corresponding aglycones ( $\triangleright$ Fig. 1, Fig. 2S, Supporting Information). In particular, biochanin $\mathrm{A}$ and glycitein appeared the most potent vasodilators, having $\mathrm{EC}_{50}$ below $30 \mu \mathrm{M}$, followed in ascending order by genistein, isoformononetin, formononetin, tectorigenin, calycosin, cladrin, prunetin, and daidzein, with $\mathrm{EC}_{50}$ ranging from 30 to $110 \mu \mathrm{M}$ ( $\triangleright$ Table 2 ).

Thereafter, the 2 most potent isoflavonoids, biochanin A and glycitein, were selected for further mechanistic experiments. Similarly to rat aorta, as is also the case with coronary arteries, both compounds induced dose-dependent vasorelaxation. The effect was not significantly modified by the absence of the vascular endothelium ( $\triangleright$ Fig. 2, Fig. 3S, Supporting Information) in any of the artery models with a small exception of higher concentration of glycitein in coronary rings. Interestingly, the $\mathrm{EC}_{50}$ of biochanin $\mathrm{A}$ on coronary arteries $(5.5 \pm 0.6 \mu \mathrm{M})$ was lower than that on rat aortas $(25.4 \pm 2.2 \mu \mathrm{M})$ and that of glycitein $(16.2 \pm 1.0 \mu \mathrm{M})$. For glycitein, the difference between $\mathrm{EC}_{50}$ s for the 2 types of vessels was smaller $\left(\mathrm{EC}_{50} \mathrm{~s}=27.5 \pm 2.8 \mu \mathrm{M}\right.$ and $16.2 \pm 1.0 \mu \mathrm{M}$ on aortas and coronary arteries, respectively). Since the effect on coronary arteries was achieved in lower concentrations, and given the similarities between porcine and human hearts [18], this model was used for further testing.

To further elucidate the mechanism(s) of the selected isoflavonoids, endothelium-denuded coronary arteries pretreated with biochanin $\mathrm{A}(3,10$, and $30 \mu \mathrm{M})$ or glycitein $(10,15$, and $30 \mu \mathrm{M})$ were exposed to increasing concentrations of 4 different vasocontricting stimuli. Contractions induced by both $\mathrm{KCl}$ and $\mathrm{CaCl}_{2}$ were dose-dependently inhibited by biochanin $\mathrm{A}$. In the highest dose, biochanin $A$ equally blocked $73 \%$ of the maximal vasoconstriction caused by both inducers ( $\bullet$ Fig. 3 a). On the other hand, glycitein only caused an approximate $25 \%$ reduction of the maximal effect of $\mathrm{KCl}$ and did not significantly alter the contraction induced by the maximal concentration of $\mathrm{CaCl}_{2}$. However, $30 \mu \mathrm{M}$ of glycitein partly blocked the effect of lower concentrations of $\mathrm{CaCl}_{2}$

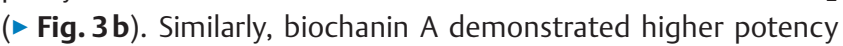
against receptor-mediated contractions induced by serotonin or thromboxane-analogue U46619. In the highest concentration, it blocked $88 \%$ and $56 \%$ of their maximal effects, respectively ( $\vee$ Fig. 3 a). On the contrary, only the highest used concentration of glycitein $(30 \mu \mathrm{M})$ managed to block, at least partially (38\%), the maximal effect of serotonin, as well as decreased the contractions induced by low concentrations of U46619 ( $\bullet$ Fig. 3 b). 


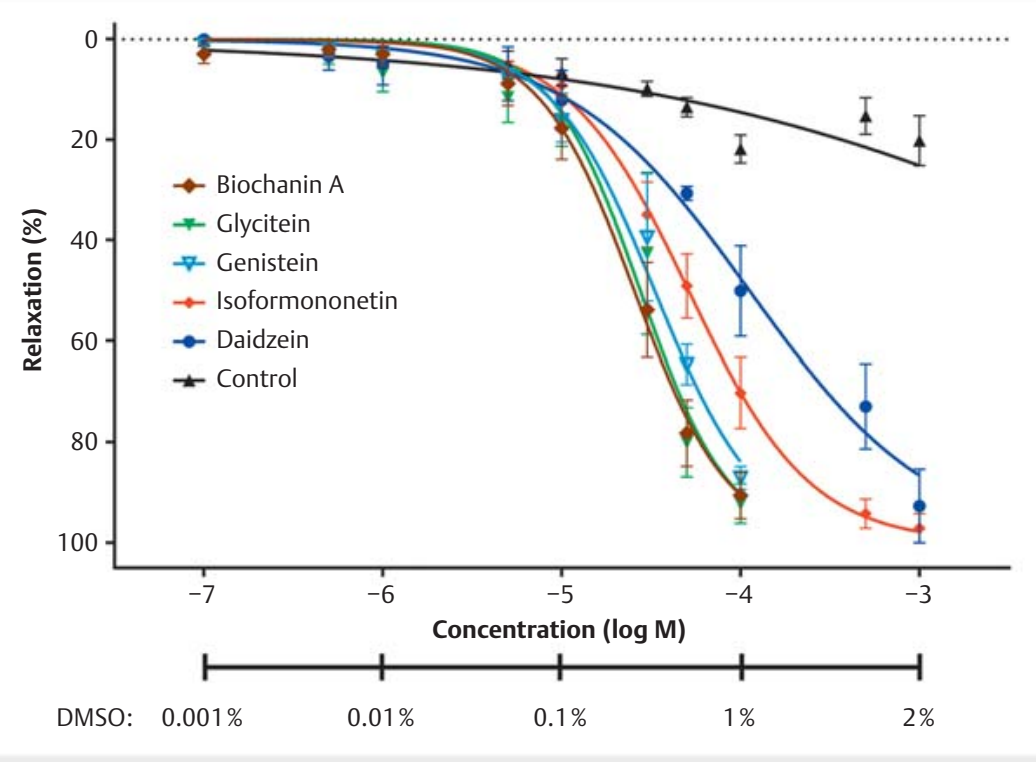

- Fig. 1 Concentration-response curves showing the vasorelaxant effect of the most potent isoflavonoid aglycones in endothelium-intact rat aortic rings, precontracted by norepinephrine $\left(10^{-5} \mathrm{M}\right)$. Relaxation is expressed as percentages of the sodium nitroprusside-induced relaxation of the vessels, $n=5$. A concentration-response curve to the solvent was used as the negative control, and the final concentration of DMSO in the organ bath is indicated below the $x$-axis.

Due to the higher potency of biochanin A, subsequent series of mechanistic experiments were performed with this isoflavonoid. Since biochanin A blocked constrictions induced by different inducers, intracellular calcium signalling could be the target of this compound. Hence, porcine coronary arteries were pre-treated with different concentrations of biochanin $\mathrm{A}$ and then exposed to increasing concentrations of Bay K8644, an activator of L-type calcium channels. Under these conditions, biochanin A dose dependently blocked the contractions ( $\bullet$ Fig. 4 ). In preliminary experiments in rat aorta, biochanin A in a concentration of $30 \mu \mathrm{M}$ also inhibited the contractions induced by phenylephrine in the absence of extracellular calcium (Fig. 4S, Supporting Information).

In a separate series of experiments, sodium nitroprusside and forskolin were used to relax precontracted porcine coronary artery rings without endothelium, by raising the intracellular levels of cyclic GMP and cyclic AMP, respectively. Co-treatment of the vessels with low concentrations of biochanin $A(2-4 \mu \mathrm{M})$ led to a significant potentiation of the sodium nitroprusside-induced re-

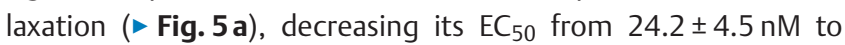
$9.4 \pm 6.3 \mathrm{nM}$. However, no significant influence on the effect of forskolin was observed ( $\mathbf{F i g} \mathbf{5} \mathbf{5}$ ), indicating that biochanin A might stimulate the cGMP, but not the cAMP, related vasodilatory pathway.

A notable step within the cGMP pathway, activated by nitric oxide, is the conversion of GTP to cGMP, by soluble guanylyl cyclase. The presence of ODQ $\left(10^{-6} \mathrm{M}\right)$, a selective inhibitor of this enzyme, delayed the onset of the vasorelaxant response to biochanin $A$ in endothelium-denuded coronary rings ( $\triangleright$ Fig. 6 a). The $E_{50}$ shifted from $5.1 \pm 0.8$ to $6.8 \pm 0.5 \mu \mathrm{M}$, while the achieved maximal relaxation was not affected. Additionally, in order to determine whether the production of prostanoids is involved in the
- Table $2 \mathrm{EC}_{50}$ of the vasodilatory response to isoflavonoid aglycones in rat thoracic aortic rings.

\begin{tabular}{|l|c|l|}
\hline Isoflavonoid & $\mathrm{EC}_{\mathbf{5 0}}(\boldsymbol{\mu M})$ & $\begin{array}{l}\mathbf{9 5} \% \text { confidence } \\
\text { interval }(\boldsymbol{\mu M})\end{array}$ \\
\hline Biochanin A & 25.44 & 21.41 to 30.24 \\
\hline Glycitein & 27.51 & 22.36 to 33.84 \\
\hline Genistein & 32.09 & 29.40 to 37.26 \\
\hline Isoformononetin & 51.19 & 44.46 to 58.93 \\
\hline Formononetin & 59.53 & 56.76 to 62.43 \\
\hline Tectorigenin & 62.40 & 56.10 to 69.42 \\
\hline Calycosin & 68.38 & 58.65 to 79.71 \\
\hline Cladrin & 72.30 & 64.63 to 80.87 \\
\hline Prunetin & 74.14 & 48.25 to 113.92 \\
\hline Daidzein & 112.09 & 82.46 to 152.37 \\
\hline
\end{tabular}

The data are derived from 5 experiments.

mechanism of action of biochanin A, coronary artery rings without endothelium were incubated with indomethacin $\left(10^{-5} \mathrm{M}\right)$ prior to the administration of the isoflavonoid. However, the inhibition of cyclooxygenase did not cause any alteration in the vasorelaxant effect ( $\vee$ Fig. $\mathbf{6}$ b).

\section{Discussion}

Isoflavonoids have always attracted scientific interest because of their potentially positive effects on human beings. The studies testing their vasorelaxant activity have typically involved 1,2 , or 


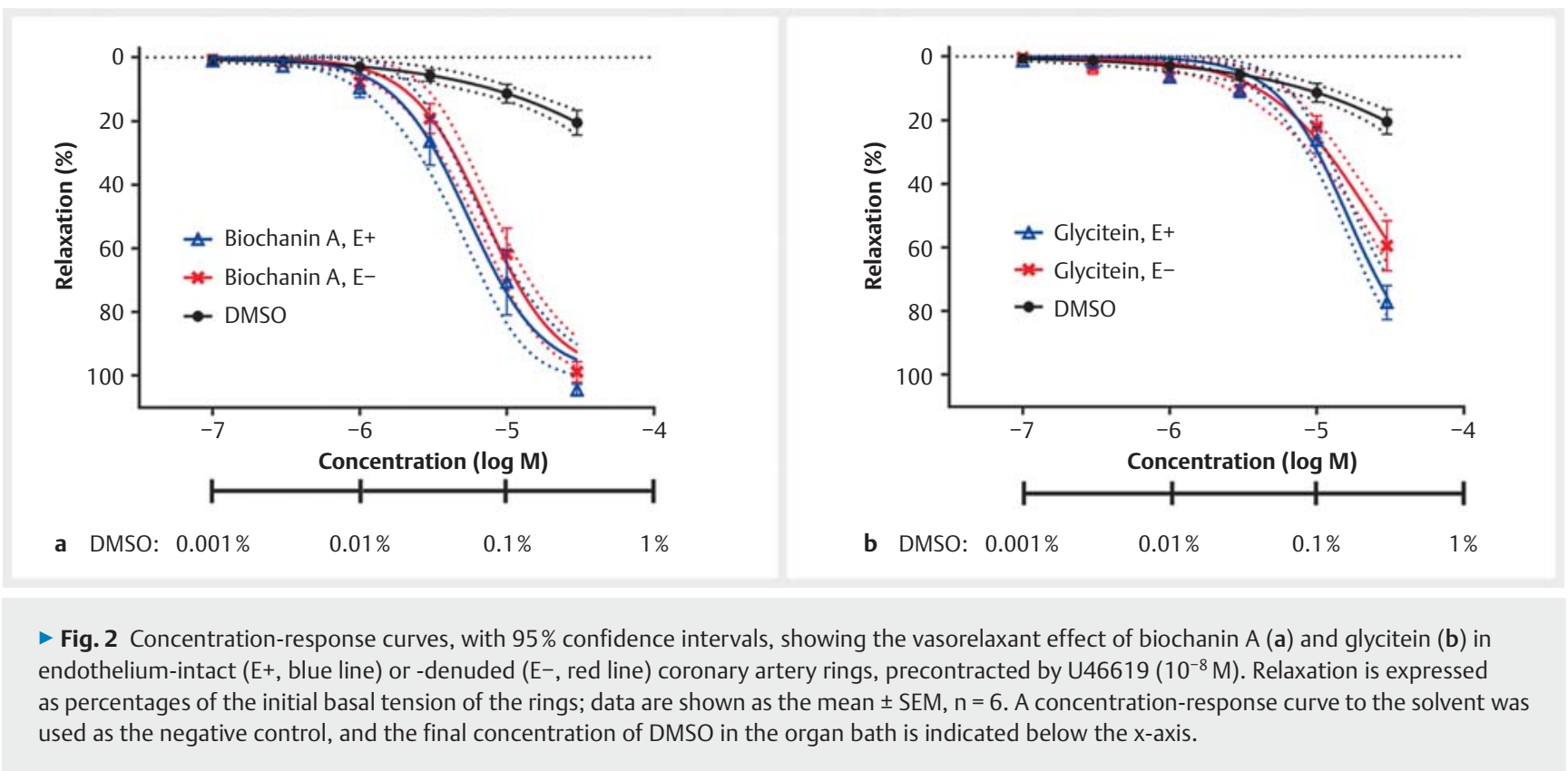

several isoflavonoids. Due to various experimental approaches, the comparison is difficult, if even possible at all. To the best of our knowledge, this is the first comparative investigation of the vascular effects of 16 isoflavonoids. Six of them, namely isoformononetin, cladrin, tectorigenin, tectoridin, ononin, and glycitin, had never been tested as vasodilators before. Interestingly, isoformononetin, tectorigenin, and cladrin appeared more potent than daidzein in this study. Previous articles showed different potencies of several isoflavones on various arteries [5, 7, 11, 15, 16, 19-22]. Small discrepancies between the aforementioned studies might derive from the use of different animal, breed, or tissue models or may be due to different vasoconstrictors used to precontract the tested arteries. In our experiments, porcine coronary arteries appeared to be more sensitive than rat aortas to both biochanin $A$ and glycitein, but this difference was more pronounced in the case of biochanin A. Summing up the available studies, biochanin A was always a more potent vasodilator than other isoflavonoids when tested on $\mathrm{KCl}$ or UTP precontracted rabbit coronary and basilar arteries $[11,15]$. There is only 1 partial exception: formononetin reached the level of the activity of biochanin A in phenylephrine precontracted rat aorta [13].

Concerning the structure-activity relationship, our results suggest that the methoxylation of $4^{\prime}$ carbon of the isoflavonoid structure increases vasorelaxant potency, since biochanin A and formononetin demonstrate higher potency than the corresponding structures of genistein and daidzein respectively, which lack the specific methoxylation. Moreover, genistein appears more active than daidzein and glycitein more active than tectorigenin. The only structural difference between these 2 pairs of compounds is the presence of 5-hydroxyl group in the cases of genistein and tectorigenin. Hence this substituent has different impact on the vasodilatory effect. The presence of a 3'-methoxy group does not improve the effect, as can be deduced by making a comparison of calycosin with cladrin. The presence of a 6- or 7-methoxy group can increase or decrease the potency, apparently depend- ing on other substitutions. For example, in the case of tectorigenin, the methoxy group at C6 decreased the potency vs. genistein, while in the case of glycitein, the additional methoxy group at C6 increased the potency vs. daidzein. The probable reason for this paradoxical effect may lie in additional mechanisms of action, in particular genistein is known to be a potent inhibitor of tyrosine kinases [23]. Additionally, in all cases, the presence of sugar moiety at any position of the isoflavonoid core abolished or significantly decreased the efficacy.

Based on this initial screening, we selected the 2 most active compounds, glycitein and biochanin A. Quite surprisingly, although glycitein is present in relatively high amounts in soy foods and some dairy products [9], little is known about its vasoactive properties. In fact, it has been mainly tested as a part of mixed isoflavone preparations in the past [24]. Therefore, it was unexpected that glycitein is a potent vasodilator, with an $\mathrm{EC}_{50}$ comparable to that of biochanin A. Its effect was endothelium-independent, but the inhibition of contraction by $\mathrm{KCl}, \mathrm{CaCl}_{2}$, serotonin, and U46619 was achieved in high concentrations and was only partial. Due to this, we concentrated only on the more active biochanin $A$ in next experiments.

In the case of biochanin A, more data showing its vasorelaxing properties are available. These include rabbit coronary and basilar arteries [11,15], as well as rat aortas [8,25]. Biochanin A induces dose-dependent and endothelium-independent relaxation. This study confirmed these outcomes in rat aortas and newly documented it in porcine coronary arteries as well.

Although these aforementioned studies confirmed the effects of biochanin, the precise mechanism of action was unknown. Before this study was initiated, there was rather only negative evidence reporting that biochanin A did not affect the production of nitric oxide or prostaglandins $[8,25]$. The only known mechanism of action was a partial effect of biochanin $A$ on the activation of ATP-sensitive and large-conductance $\mathrm{Ca}^{2+}$-activated $\mathrm{K}^{+}$channels $[8,25]$. Since these effects cannot fully explain the ability of 


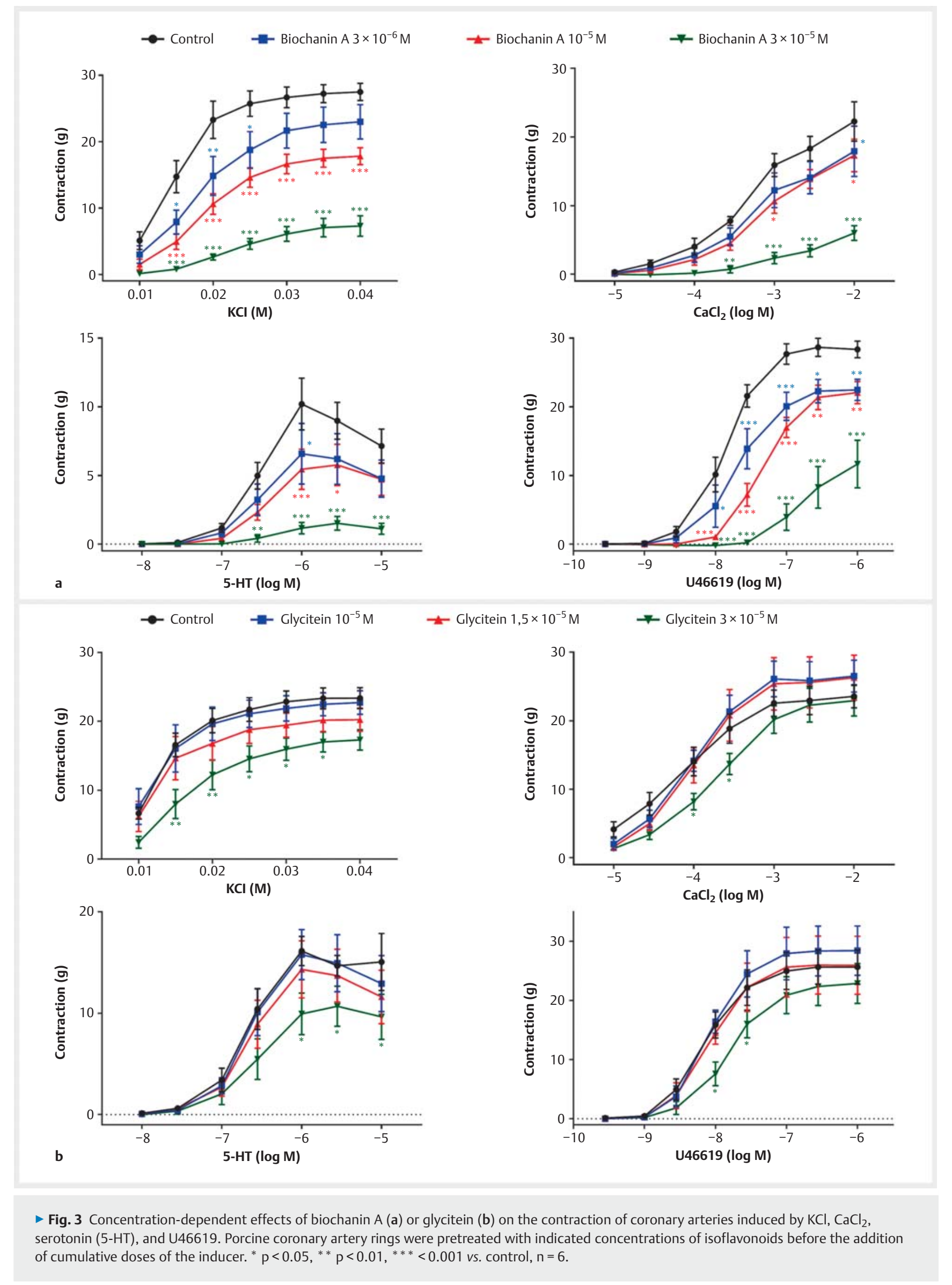


this compound to evoke complete or almost complete relaxation of the tested vessels, the mechanism of action was further sought. To investigate it, 4 different vasoconstrictive impulses were tested initially. In all these cases, biochanin A dose dependently blocked or markedly diminished their effects in endothelium-denuded coronary arteries.

Both $\mathrm{CaCl}_{2}$ and potassium-induced depolarization lead to extracellular $\mathrm{Ca}^{2+}$ influx through the L-type voltage gated $\mathrm{Ca}^{2+}$ channels [26]. Serotonin and U46619 cause vasoconstriction through $5-\mathrm{HT}_{2 \mathrm{~A}}$ and thromboxane $\mathrm{A}_{2} \mathrm{Gq}$ protein-coupled receptors, respectively $[26,27]$. Considering that the effects of both are inhibited by biochanin $A$, we presumed that this isoflavonoid rather acts on downstream contraction pathways than on the receptor level. Biochanin A (1-10 $\mu \mathrm{M})$ also managed to inhibit the contractions induced by phenylephrine, another agonist on Gq proteincoupled receptors, in rat aortas [25]. Similarly, in this study, biochanin A caused the vasodilation of norepinephrine precontracted vessels in the same experimental model ( $\boldsymbol{\text { Fig. }} \mathbf{1}$ ). We hypothesized that the inhibition was mediated at the level of L-type channels, because these channels are involved in Gq protein-initiated vasoconstriction [26] and thus their activation seems to be a common step between the ion and receptor-mediated pathways. For this reason, we decided to confirm this assumption experimentally for the first time. The achieved results indicate that biochanin A blocks the effect of Bay K8644 and thus the influx of calcium through L-type channels into vascular smooth muscles in concentrations above $10 \mu \mathrm{M}$. Although this seems to be the major mechanism of action, looking at the vasorelaxant curves of biochanin $\mathrm{A}$, it is apparent that this compound also has vasodilatory effects in lower concentrations in coronary arteries ( $\bullet$ Fig. 2 a).

For this reason, other mechanisms of action, which might be relevant in lower concentrations, were also considered. Indeed, low concentrations ( $2-4 \mu \mathrm{M})$ of biochanin A potentiated the relaxation induced by cumulative doses of sodium nitroprusside. Moreover, biochanin A-induced relaxation was delayed in the presence of a soluble guanylyl cyclase inhibitor (ODQ). Such potentiating effect can be limited to coronary vasculature since it was not observed in rat aortic rings [8], and Torregrosa et al. (2003) reported that soluble guanylyl cyclase inhibitors (ODQ, NS2028) did not affect the biochanin A-induced dilation of rabbit basilar arteries. In addition to the aforementioned differences in vascular beds or potential interspecies differences, the discrepancy may also depend on the use of a high concentration of the inhibitors $\left(10^{-5} \mathrm{M}\right)$ by the afore-mentioned researchers. Collectively, the presented data reveal that biochanin A activates the cGMP pathway in units of micromolar concentrations, while in slightly higher concentrations, it acts as an L-type calcium channel blocker ( $\bullet$ Fig. 7). From this point of view, it is interesting that biochanin A imitates the mechanism of action of estradiol $[28,29]$. Our preliminary results (Fig. 4S, Supporting Information) in rat aorta indicate that an inhibiting effect on calcium release from intracellular stores might be also involved when higher concentrations of the compound are used.

It can be concluded that isoflavonoids started to exhibit direct vasorelaxant activity in tens of $\mu \mathrm{M}$, while even lower concentrations of biochanin A significantly potentiated the effect of sodium nitroprusside. Such results are of potential clinical interest, since

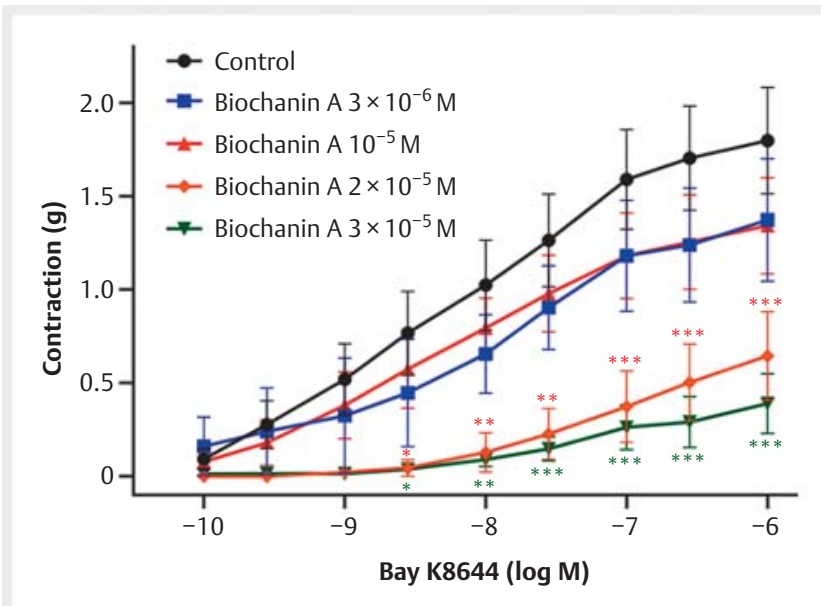

- Fig. 4 Concentration-dependent effects of biochanin A on vessel contraction induced by the activation of L-type channels. Porcine coronary artery rings were pretreated with indicated concentrations of biochanin A before the addition of cumulative doses of calcium channel activator BAY K8644. * $\mathrm{p}<0.05,{ }^{* *} \mathrm{p}<0.01$, $* * *<0.001$ vs. control, $\mathrm{n}=5$.

concentrations up to $2 \mu \mathrm{M}$ might be feasible in human blood circulation, after eating a special diet or being administered food supplements rich in isoflavones $[30,31]$. Indeed, biochanin A is present in chickpeas (Cicer arietinum) [32], alfalfa (Medicago sativa) [33], peanuts (Arachis hypogaea), almonds (Prunus dulcis), walnuts (Juglans regia), and pecans (Carya illinoinensis) [34,35], and broadly used food supplements derived from red clover (Trifolium pratense) contain relatively high amounts of the isoflavone too [30]. This study provided evidence about the vasorelaxant of action of glycitein and deeper insight into the mode of action of biochanin A.

\section{Materials and Methods}

\section{Tested compounds}

Calycosin (purity: 99\%), cladrin (98\%), and isoformononetin (99\%) were purchased from Phytolab. Biochanin A ( $\geq 99 \%)$, daidzin ( $\geq 99 \%$ ), formononetin ( $\geq 99 \%$ ), genistin ( $\geq 99 \%)$, glycitein ( $\geq 95 \%$ ), glycitin ( $\geq 95 \%$ ), ononin ( $\geq 99 \%)$, prunetin ( $\geq 95 \%$ ), and puerarin ( $\geq 99 \%$ ) were purchased from Extrasynthese and daidzein $(\geq 98 \%$ ), genistein ( $\geq 98 \%$ ), tectoridin ( $\geq 98 \%$ ), and tectorigenin $(\geq 98 \%$ ) from Sigma-Aldrich.

\section{Chemicals}

Urethane, norepinephrine bitartrate (NE), phenylephrine hydrochloride, sodium nitroprusside, acetylcholine iodide, bradykinin acetate salt, nifedipine, indomethacin, serotonin (5-HT), forskolin, ethylenediaminetetraacetic acid (EDTA), dimethyl sulfoxide (DMSO), $\mathrm{KCl}$, and $\mathrm{CaCl}_{2} \cdot 2 \mathrm{H}_{2} \mathrm{O}$ were purchased from Sigma-Aldrich, [1H-[1,2,4]oxadiazolo-[4, 3-a]quinoxalin-1-one] (ODQ) from Enzo Life Sciences, U46619 from Cayman Chemical Company, and Bay K8644 from Axon Medchem BV. $\mathrm{NaCl}$, $\mathrm{NaHCO}_{3}$, and D-glucose were provided by PENTA s.r.o., $\mathrm{KCl}$ and 

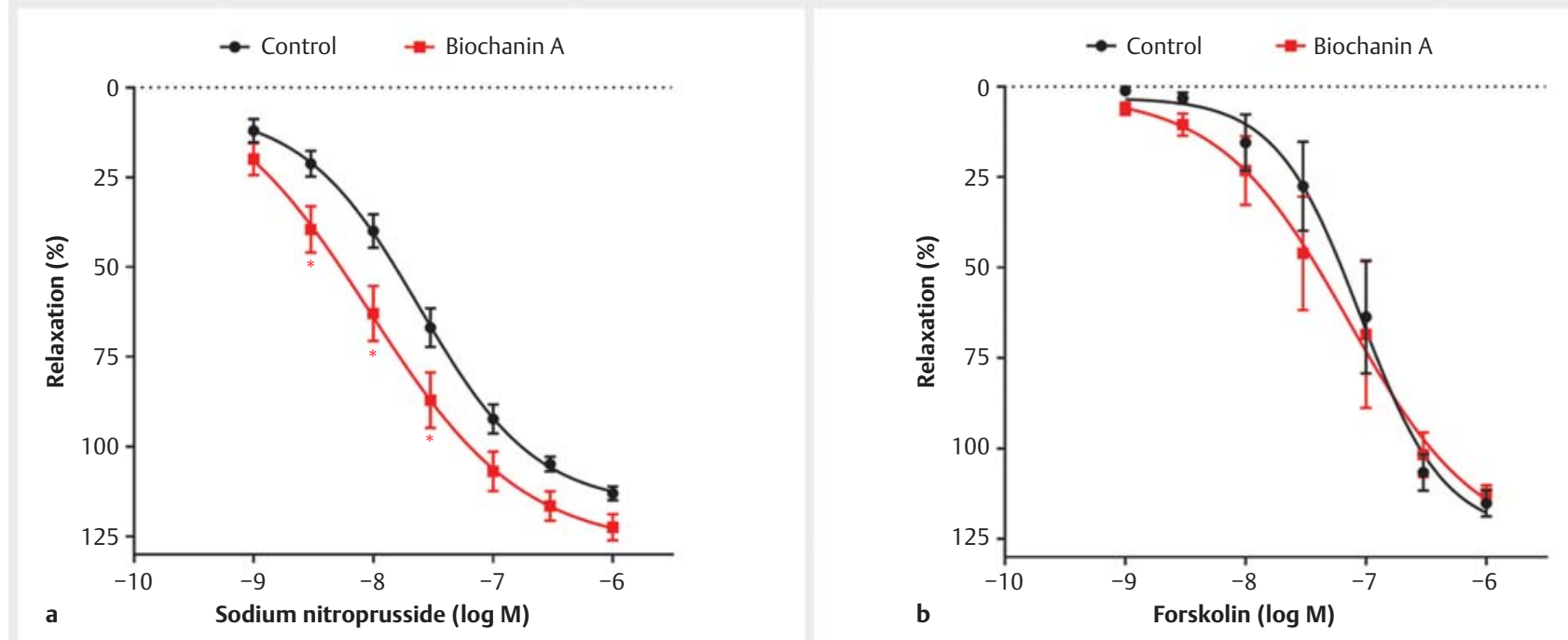

- Fig. 5 The effect of biochanin A on relaxation induced by sodium nitroprusside (a) and forskolin (b). After exposure of endothelium-denuded coronary artery rings to biochanin $\mathrm{A}(2-4 \mu \mathrm{M}$, able to cause $20 \%$ of relaxation), relaxation was induced by the addition of cumulative doses of either nitroprusside or forskolin. Relaxation is expressed as percentages of the initial basal tension of the rings. * a difference at $\mathrm{p}<0.05$ between corresponding values, $\mathrm{n}=5$.

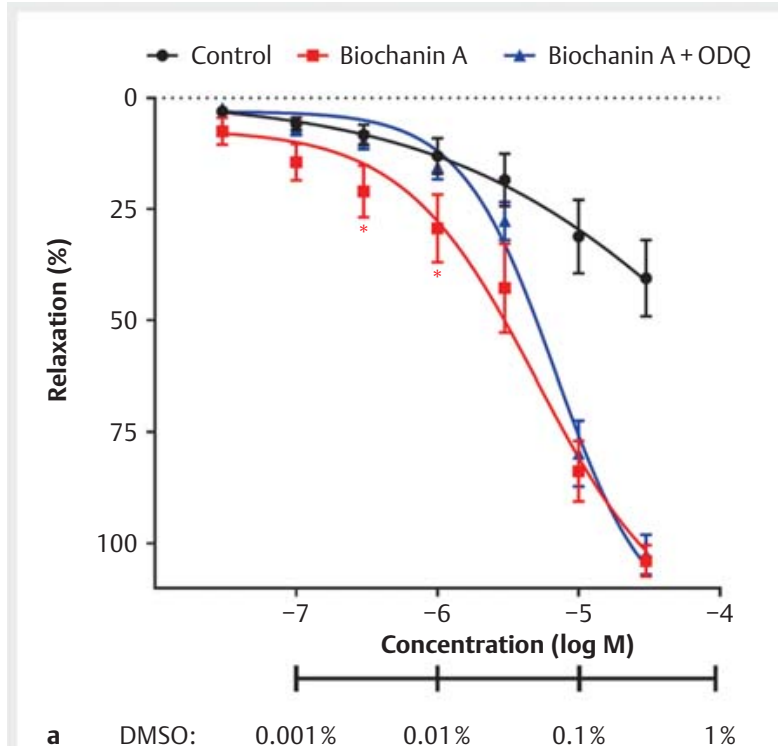

- Fig. 6 The influence of inhibition of guanylyl cyclase (a) and cyclooxygenase (b) on biochanin A-induced vasorelaxation. Endothelium-denuded coronary artery rings were incubated with ODQ $\left(\mathrm{a}, 10^{-6} \mathrm{M}\right)$ or indomethacin $\left(\mathrm{b}, 10^{-5} \mathrm{M}\right)$ before cumulative doses of biochanin $\mathrm{A}$ were administered. Relaxation is expressed as percentages of the initial basal tension of the rings. ${ }^{*}$ indicates a difference $(p<0.05)$ between the absence and presence of the inhibitor, $n=6$. A concentration-response curve to the solvent was used as the negative control, and the final concentration of DMSO in the organ bath is indicated below the $\mathrm{x}$-axis.

$\mathrm{MgSO}_{4} .7 \mathrm{H}_{2} \mathrm{O}$ by Erba Lachema s.r. o., and $\mathrm{KH}_{2} \mathrm{PO}_{4}$ by Dr. Kulich Pharma s.r.o.

Krebs solution had the following composition in $\mathrm{mM}: \mathrm{NaCl} 119$, $\mathrm{KCl}$ 4.7, $\mathrm{CaCl}_{2} .2 \mathrm{H}_{2} \mathrm{O} 1.25, \mathrm{KH}_{2} \mathrm{PO}_{4} 1.18, \mathrm{MgSO}_{4} .7 \mathrm{H}_{2} \mathrm{O}$ 1.17, $\mathrm{NaHCO}_{3} 25$, and D-glucose $11(\mathrm{pH} 7.4)$.

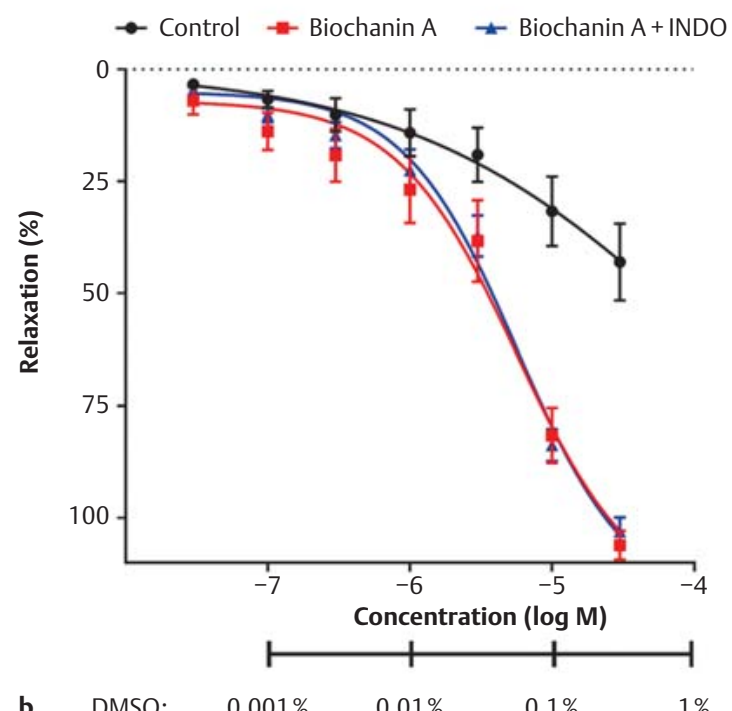

\section{Experiments on rat aortas and porcine coronary arteries}

The experiments were carried out on aortas excised from male Wistar Han rats, obtained from Charles River or on pig hearts collected from a local slaughterhouse. The initial screening experiments followed commonly used methods (see supplementary 


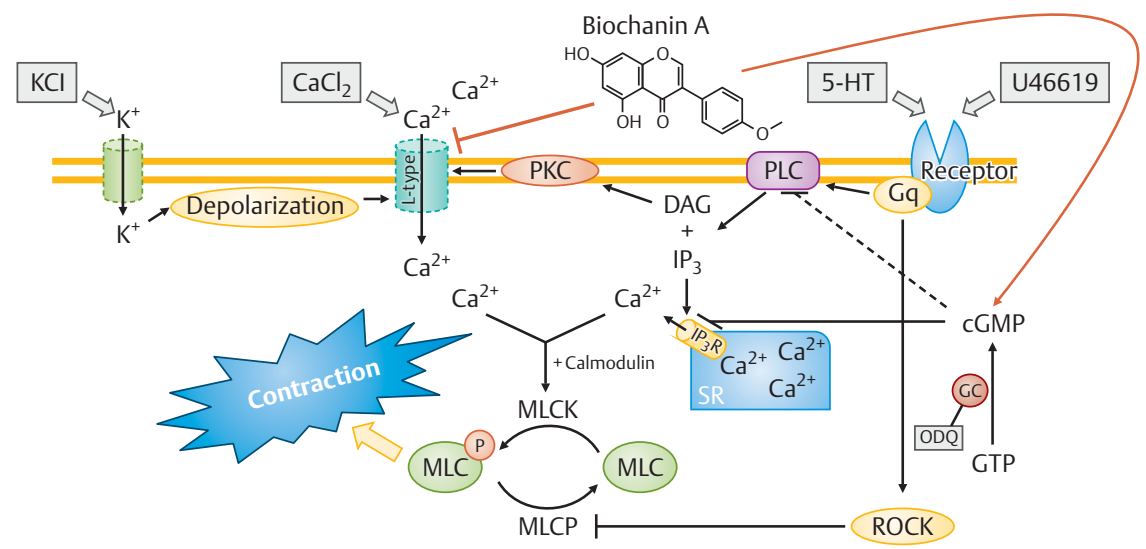

- Fig. 7 Scheme depicting the proposed mechanism of action of biochanin A on smooth muscle cells. In higher concentrations, biochanin A can also likely have an effect on the release of calcium from sarcoplasmic reticulum (not shown). cGMP = cyclic guanosine monophosphate, DAG = diacylglycerol, GC = guanylate cyclase, GTP = guanosine triphosphate, $I_{3}=$ inositol 1,4,5-triphosphate, $I_{3} R=$ inositol 1,4,5-triphosphate receptor, $\mathrm{MLC}=$ myosin light chain, $\mathrm{MLCK}=$ myosin light chain kinase, $\mathrm{MLCP}=$ myosin light chain phosphatase, $\mathrm{ODQ}=1 \mathrm{H}-[1,2,4]$ oxadiazolo- $[4,3$-a $]$ quinoxalin-1-one, $\mathrm{P}$ = phosphate group, $\mathrm{PKC}=$ protein kinase $\mathrm{C}, \mathrm{PLC}=$ phospholipase $\mathrm{C}, \mathrm{ROCK}=$ rho-associated protein kinase, $\mathrm{SR}=$ sarcoplasmic reticulum, 5-HT = 5-hydroxytryptamine.

data for details). The study (reg. No. MSMT-7041/2014-10) was approved on March 7, 2014 by the Ministry of Education, Youth and Sports and conformed to The Guide for the Care and Use of Laboratory Animals published by the U.S. National Institutes of Health (8th edition, revised 2011, ISBN-13: 978-0-309-15400-0).

\section{Determination of the mechanism of the vasorelaxant effect}

The arterial rings were constricted with U46619 (6-16 nM) or NE $(10 \mu \mathrm{M})$, and cumulative doses of isoflavonoids $(0.1-100 \mu \mathrm{M})$ or vehicle (DMSO, 0.001-1\%) were applied. The next dose was always added after stabilization of the relaxant response to the previous dose. Enzyme inhibitors (ODQ, $10^{-6} \mathrm{M}$ /indomethacin, $10^{-5} \mathrm{M}$, dissolved in DMSO and $5 \%$ aqueous sodium carbonate solution respectively) were added in the chamber $30 \mathrm{~min}$ prior to U46619 application when needed. The addition of sodium nitroprusside $(10 \mu \mathrm{M})$ induced the maximal $(100 \%)$ relaxation of the arterial rings at the end of each experiment.

\section{Inhibition of contractile responses}

For the determination of the inhibition of contractile responses, coronary endothelium-denuded rings were exposed to 3 different concentrations ( 3 or 15,10 , and $30 \mu \mathrm{M}$ ) of the selected isoflavonoids for 30 min before the cumulative administration of increasing concentrations of either $\mathrm{KCl}, 5-\mathrm{HT}, \mathrm{U} 46619$, or $\mathrm{CaCl}_{2}$ in the presence of $40 \mathrm{mM} \mathrm{KCl}$.

\section{Inhibition of the effect of Bay K8644}

Endothelium-denuded coronary rings were treated with 4 different concentrations $(3,10,20$, and $30 \mu \mathrm{M})$ of biochanin $A$ in the presence of $15 \mathrm{mM} \mathrm{KCl}$ and protected from intense light. Then, Bay K8644, an L-type calcium channel activator, was applied cumulatively $\left(10^{-10}-10^{-6} \mathrm{M}\right)$ to induce contraction of the smooth muscles.
Effect on relaxation induced by activators of cyclic nucleotide synthesis

Endothelium-denuded coronary artery rings were contracted with U46619 (6-16 nM) and then exposed to a low concentration of isoflavonoid $(2-4 \mu \mathrm{M})$, so that relaxation to about $15-20 \%$ of the maximum amount was induced. Subsequently, concentration-dependent relaxation was caused by the administration of cumulative doses ( $1 \mathrm{nM}-1 \mu \mathrm{M})$ of either sodium nitroprusside or forskolin, which activate guanylyl and adenylyl cyclase, respectively.

\section{Statistical analysis}

Data were presented as mean \pm S.E.M. The number (n) of different experiments was always mentioned. The $\mathrm{EC}_{50}$ value corresponded to the concentration of the isoflavonoid inducing $50 \%$ of the vasorelaxant response, determined by GraphPad Prism 7 (GraphPad Software, Inc.). The mean values were compared by analyzing the variance followed by the Sidak posthoc test employing GraphPad Prism 7. The difference was considered to be significant when a p-value less than 0.05 was found. Concentration-relaxation curves were compared using 95\% confidence intervals, plotted by the above-mentioned software.

\section{Supporting information}

Detailed description of the experimental procedures, as well as the graphs depicting the effect of the isoflavonoids of lower potency and the mechanism of action tested in rat aorta are available as Supporting Information.

\section{Acknowledgements}

This work was supported by the EFSA-CDN project (grant number: CZ.02.1.01/0.0/0.0/16_019/0000841) co-funded by the ERDF and Charles University (grant number: SVV 260 414). English language was revised by the agency "theBESTtranslation". 


\section{Conflict of Interest}

The authors declare that they have no conflict of interest.

\section{References}

[1] Kokubo Y, Iso H, Ishihara J, Okada K, Inoue M, Tsugane S, Group JS. Association of dietary intake of soy, beans, and isoflavones with risk of cerebral and myocardial infarctions in Japanese populations: the Japan Public Health Center-based (JPHC) study cohort I. Circulation 2007; 116: 25532562

[2] Pase MP, Grima NA, Sarris J. The effects of dietary and nutrient interventions on arterial stiffness: a systematic review. Am J Clin Nutr 2011; 93: 446-454

[3] Sagara M, Kanda T, NJelekera M, Teramoto T, Armitage L, Birt N, Birt C, Yamori Y. Effects of dietary intake of soy protein and isoflavones on cardiovascular disease risk factors in high risk, middle-aged men in Scotland. J Am Coll Nutr 2004; 23: 85-91

[4] Setchell KD. Soy isoflavones - benefits and risks from nature's selective estrogen receptor modulators (SERMs). J Am Coll Nutr 2001; 20: 354S362S; discussion 381S-383S

[5] Li T, Zhong Y, Tang T, Luo J, Cui H, Fan R, Wang Y, Wang D. Formononetin induces vasorelaxation in rat thoracic aorta via regulation of the PI3K/ PTEN/Akt signaling pathway. Drug Des Devel Ther 2018; 12: 3675-3684

[6] Tseng HH, Vong CT, Leung GP, Seto SW, Kwan YW, Lee SM, Hoi MP. Calycosin and formononetin induce endothelium-dependent vasodilation by the activation of large-conductance $\mathrm{Ca}(2+)$-activated $\mathrm{K}(+)$ channels (BKCa). Evid Based Complement Alternat Med 2016; 2016: 5272531

[7] Yeung DK, Leung SW, Xu YC, Vanhoutte PM, Man RY. Puerarin, an isoflavonoid derived from Radix puerariae, potentiates endothelium-independent relaxation via the cyclic AMP pathway in porcine coronary artery. Eur J Pharmacol 2006; 552: 105-111

[8] Choi S, Jung WS, Cho NS, Ryu KH, Jun JY, Shin BC, Chung JH, Yeum CH. Mechanisms of phytoestrogen biochanin A-induced vasorelaxation in renovascular hypertensive rats. Kidney Res Clin Pract 2014; 33: 181-186

[9] Socas-Rodriguez B, Herrera-Herrera AV, Hernandez-Borges ], RodriguezDelgado MA. Multiresidue determination of estrogens in different dairy products by ultra-high-performance liquid chromatography triple quadrupole mass spectrometry. J Chromatogr A 2017; 1496: 58-67

[10] Krizova L, Vesely A, Trinacty J, Schulzova V, Hurajova A, Hajslova J, Kvasnickova E, Havlikova S. Changes in isoflavones concentrations in cheese during processing and ripening. Acta Univ Agric Silvic Mendelianae Brun 2011; 59: 153-162

[11] Torregrosa G, Burguete MC, Perez-Asensio FJ, Salom JB, Gil JV, Alborch E. Pharmacological profile of phytoestrogens in cerebral vessels: in vitro study with rabbit basilar artery. Eur J Pharmacol 2003; 482: 227-234

[12] Teede HJ, McGrath BP, DeSilva L, Cehun M, Fassoulakis A, Nestel PJ. Isoflavones reduce arterial stiffness: a placebo-controlled study in men and postmenopausal women. Arterioscler Thromb Vasc Biol 2003; 23: 1066-1071

[13] Wu JH, Li Q, Wu MY, Guo DJ, Chen HL, Chen SL, Seto SW, Au AL, Poon CC, Leung GP, Lee SM, Kwan YW, Chan SW. Formononetin, an isoflavone, relaxes rat isolated aorta through endothelium-dependent and endothelium-independent pathways. J Nutr Biochem 2010; 21: 613-620

[14] Sun XH, Ding JP, Li H, Pan N, Gan L, Yang XL, Xu HB. Activation of largeconductance calcium-activated potassium channels by puerarin: the underlying mechanism of puerarin-mediated vasodilation. J Pharmacol Exp Ther 2007; 323: 391-397

[15] Figtree GA, Griffiths H, Lu YQ, Webb CM, MacLeod K, Collins P. Plant-derived estrogens relax coronary arteries in vitro by a calcium antagonistic mechanism. J Am Coll Cardiol 2000; 35: 1977-1985

[16] Lee MY, Leung SW, Vanhoutte PM, Man RY. Genistein reduces agonistinduced contractions of porcine coronary arterial smooth muscle in a cyclic AMP-dependent manner. Eur J Pharmacol 2004; 503: 165-172
[17] Xu YC, Leung SW, Yeung DK, Hu LH, Chen GH, Che CM, Man RY. Structure-activity relationships of flavonoids for vascular relaxation in porcine coronary artery. Phytochemistry 2007; 68: 1179-1188

[18] Lelovas PP, Kostomitsopoulos NG, Xanthos TT. A comparative anatomic and physiologic overview of the porcine heart. J Am Assoc Lab Anim Sci 2014; 53: 432-438

[19] Kim B, Jo C, Choi HY, Lee K. Prunetin relaxed isolated rat aortic rings by blocking calcium channels. Molecules 2018; 23: 2372

[20] Mishra SK, Abbot SE, Choudhury Z, Cheng M, Khatab N, Maycock NJ, Zavery A, Aaronson PI. Endothelium-dependent relaxation of rat aorta and main pulmonary artery by the phytoestrogens genistein and daidzein. Cardiovasc Res 2000; 46: 539-546

[21] Sun T, Liu R, Cao YX. Vasorelaxant and antihypertensive effects of formononetin through endothelium-dependent and -independent mechanisms. Acta Pharmacol Sin 2011; 32: 1009-1018

[22] Wu XL, Wang YY, Cheng J, Zhao YY. Calcium channel blocking activity of calycosin, a major active component of Astragali radix, on rat aorta. Acta Pharmacol Sin 2006; 27: 1007-1012

[23] Wijetunge S, Aalkjaer C, Schachter M, Hughes AD. Tyrosine kinase inhibitors block calcium channel currents in vascular smooth muscle cells. Biochem Biophys Res Commun 1992; 189: 1620-1623

[24] Yamaguchi K, Honda H, Wakisaka C, Tohei A, Kogo H. Effects of phytoestrogens on acetylcholine- and isoprenaline-induced vasodilation in rat aorta. Jpn J Pharmacol 2001; 87: 67-73

[25] Wang HP, Gao Q, Mei RH, Zhao MH, Lu Y, Li XY, Bruce IC, Xia Q. Mechanisms underlying biochanin A-induced relaxation of the aorta differ between normotensive and hypertensive rats. Clin Exp Pharmacol Physiol 2006; 33: 802-807

[26] Nobe K, Paul RJ. Distinct pathways of $\mathrm{Ca}(2+)$ sensitization in porcine coronary artery: effects of Rho-related kinase and protein kinase $\mathrm{C}$ inhibition on force and intracellular $\mathrm{Ca}(2+)$. Circ Res 2001; 88: 1283-1290

[27] Miyata K, Shimokawa H, Higo T, Yamawaki T, Katsumata N, Kandabashi T, Tanaka E, Takamura Y, Yogo K, Egashira K, Takeshita A. Sarpogrelate, a selective 5-HT2A serotonergic receptor antagonist, inhibits serotonininduced coronary artery spasm in a porcine model. J Cardiovasc Pharmacol 2000; 35: 294-301

[28] White RE, Darkow DJ, Lang JL. Estrogen relaxes coronary arteries by opening BKCa channels through a cGMP-dependent mechanism. Circ Res 1995; 77: 936-942

[29] Han SZ, Karaki H, Ouchi Y, Akishita M, Orimo H. 17 beta-Estradiol inhibits $\mathrm{Ca} 2+$ influx and $\mathrm{Ca} 2+$ release induced by thromboxane $\mathrm{A} 2$ in porcine coronary artery. Circulation 1995; 91: 2619-2626

[30] Setchell KD, Brown NM, Desai P, Zimmer-Nechemias L, Wolfe BE, Brashear WT, Kirschner AS, Cassidy A, Heubi JE. Bioavailability of pure isoflavones in healthy humans and analysis of commercial soy isoflavone supplements. J Nutr 2001; 131: 1362S-1375S

[31] Setchell KD, Brown NM, Desai PB, Zimmer-Nechimias L, Wolfe B, Jakate AS, Creutzinger V, Heubi JE. Bioavailability, disposition, and dose-response effects of soy isoflavones when consumed by healthy women at physiologically typical dietary intakes. J Nutr 2003; 133: 1027-1035

[32] Wu Z, Song L, Feng S, Liu Y, He G, Yioe Y, Liu SQ, Huang D. Germination dramatically increases isoflavonoid content and diversity in chickpea (Cicer arietinum L.) seeds. J Agric Food Chem 2012; 60: 8606-8615

[33] Hloucalova P, Skladanka J, Horky P, Klejdus B, Pelikan J, Knotova D. Determination of phytoestrogen content in fresh-cut legume forage. Animals (Basel) 2016; 6: 43

[34] Chukwumah Y, Walker L, Vogler B, Verghese M. Changes in the phytochemical composition and profile of raw, boiled, and roasted peanuts. J Agric Food Chem 2007; 55: 9266-9273

[35] Kuhnle GG, Dell'Aquila C, Aspinall SM, Runswick SA, Mulligan AA, Bingham SA. Phytoestrogen content of beverages, nuts, seeds, and oils. J Agric Food Chem 2008; 56: 7311-7315 